\title{
Individual risk evaluation and interventions for mitigation in the transportation of hazardous goods: a case study
}

\author{
Elena Cristina Rada $^{1,2, *}$, Navarro Ferronato ${ }^{1}$, and Vincenzo Torretta ${ }^{1}$ \\ ${ }^{1}$ DiSTA, University of Insubria, Via G.B. Vico 46, I-21100, Varese, Italy \\ ${ }^{2}$ DICAM, University of Trento, Via Mesiano 77, I-38123, Trento, Italy
}

\begin{abstract}
The transport of hazardous substances is an economic activity essential for goods' transference chain. However, the risk in transporting hazardous materials is related to the occur of accidents causing environmental damages and public health dangerous consequences. A quite recent Italian example is the Viareggio accident (2010), which involved a train with tank cars containing liquefied petroleum gas (LPG) which caused more than thirty deaths. This paper describes the safety state in the Varese district (an area of northern Italy with a very high population density and industrial activities), with the aim at comparing the current situation (considering the risks due to the transportation of hazardous materials on the main motorways and main national roads) with a potential scenario that introduces a few mitigating interventions, such as a partial conversion from road haulage to rail transport. This comparison can be accomplished by developing the existing intermodal platforms and implementing new ones in strategic areas.
\end{abstract}

\section{Introduction}

Transportation and management of dangerous goods is cause of risk for the population which live along the routes and around production areas [1-2]. The main guidelines for risk management in the chemical industry are provided by the European Union (EU) by the Seveso Directive [3], among others. However, there is not a unified presentations of industrial risks, while activities involving hazardous materials are not wide covered by existing directives and legislation. This means that, in EU, hazardous installations and activities are not automatically and always included in territorial risk assessments [3]. As a result, information transfer from decision makers to stakeholders, such as civil services, does not exist. This situation creates huge demands for territorial risk and vulnerability management tools, especially emergency preparedness planning [4]. Moreover, risk management instruments include a very critical item represented by risk communication and population involvement [5]. The main issues in hazardous goods transportation studies are data research and collection on traffic flows, running time, characteristics of neighborhood, the existent of rail bridges and tunnels along the way, among others [6-9]. Such items are required also by

\footnotetext{
*Corresponding author: elena.rada@unitn.it
} 
customers which choose intermodal route mainly by lead-times [10]. Transport risk analysis presents more difficulties than risk analysis conducted, as instance, in a chemical industry since there are more uncertainties about potential accident dynamics and accident localization [11-12]. The main legislative references concerning the regulation of dangerous goods' transport are made by international agreements such as the ADR (European Agreement concerning the International Carriage of Dangerous Goods by Road), for road transport, and the RID (Rules concerning the Railway international transport of hazardous goods), for rail transport. Nevertheless, these agreements principally regulate container and loads features, classification and quantities of transportable goods and vehicles on board equipment. No indications are instead specified about the possible interactions among the vehicles and their loads, the infrastructures used and the surrounding environment. This approach, in the current set of rules, lack in measures aimed to manage and reduce transport risk such as rational restriction to the passage of transport of dangerous goods in areas characterized by high vulnerabilities for the population and the environment or the provision of indication about the most suitable modal split to adopt in a given territory.

The ADR is brief and simple. Its most important item is article 2, which states that, with the exception of certain extremely dangerous materials, hazardous materials may, in general, be transported internationally in wheeled vehicles, provided that two sets of conditions are met:

- $\quad$ Annex A regulates the merchandise involved, notably its packaging and labels;

- Annex B regulates the construction, equipment and use of vehicles for the transport of hazardous materials.

According to ADR and RID, nine are the main classes of dangerous goods: explosive substances and articles (class 1); gases (class 2); flammable liquids (class 3); flammable solids, self-reactive substances and solid desensitized explosives (class 4.1); substances liable to spontaneously combust (class 4.2); substances that emit flammable gases in contact with water (class 4.3); oxidizing substances (class 5.1); organic peroxides (class 5.2); toxic substances (class 6.1); infectious substances (class 6.2); radioactive material (class 7); corrosive substances (class 8); and miscellaneous dangerous substances and articles (class 9). Governance of hazardous materials transport requires complex decisions regarding regulation, routing, land use, and resources for emergency response [13-15]. Decision makers required to balance the needs of various actors, including public and private industries, and they should take a multi-hazard approach, considering the spatial dimensions of the problem and the vulnerability of their territory. Therefore, decision makers should have appropriate decision-support tools which facilitate the integration of data required [4]. In general terms, a decision support system (DSS) is a specific class of computerized information system that assists people in making decisions based on data gathered from a wide range of sources, and which could involve the stakeholders at all stages of the corresponding risk process [16]. DSS applications are not single information resources, such as databases, models or programs that graphically represent results and figures, since are a combination of integrated tools working together. The structure and design of a DSS can vary according to the skill and aptitude of the decision maker and the need of the decision-making process [17].

In this paper, the authors use a specific DSS to quantify risk due to the transport of hazardous substances through road, rail, pipeline and inland waterways [18]. The DSS allows the following evaluations [19]:

- population global risk (n. subject/year), considering the exposition to the potentially relevant incident;

- individual risk (yearly probability/person), with the hypothesis that the single person would be exposed during the entire duration of the dangerous event without protection.

This DSS allow comparing the risk distribution for dangerous substances conveyance with different methodologies. Such indications permitting the user to decide which course should 
be followed, minimizing the risk related to the transport of hazardous substances within the territory considered. The case-study refers to the Varese district, in the Lombardy region of northern Italy, which is an area densely populated and with a diffuse presence of industrial activities. The aim of the paper is the comparison of the current scenario (considering the risks produced by the transportation of hazardous materials on the main motorways and most important national roads) with a potential scenario obtained by introducing some mitigating interventions, such as a partial conversion from road haulage to rail transport, although road transport is the most frequently utilized means of transporting hazardous goods throughout Europe [20] particularly in Italy. As instance, in Lombardy, $87 \%$ of the total amount of transported hazardous goods is carried by road [21]. So, the development of intermodal capacities is of utmost importance in order to identify alternative solutions to road transportation [22]. For that purpose, the comparison provided by this study, accomplished by developing the existing intermodal platforms and implementing new ones in strategic areas, according to other similar experiences described in the technical literature [23] allow considering what transport methodology could reduce convey risk.

\section{Materials and methods}

Varese is an Italian province with about 880,000 inhabitants and a population density of 742 $\mathrm{inh} / \mathrm{km}^{2}$. The current economic state is mainly boosted by the numerous industries which are scattered within the whole area. Since Varese is one of the province closed to Milan and the big lakes of northern Italy, the transport facilities are developed and many time trafficked due to the many commercial activities and the tourism. Indeed, five important motorways cross through the province: A8 Milan-Varese, A9 Como-Chiasso, A8/A26 Gallarate-Gattico, A36 and A60, among other provincial and national ways (Figure 1), so that Varese is considered one important economic pole for the Lombardy region, where the province is inserted.

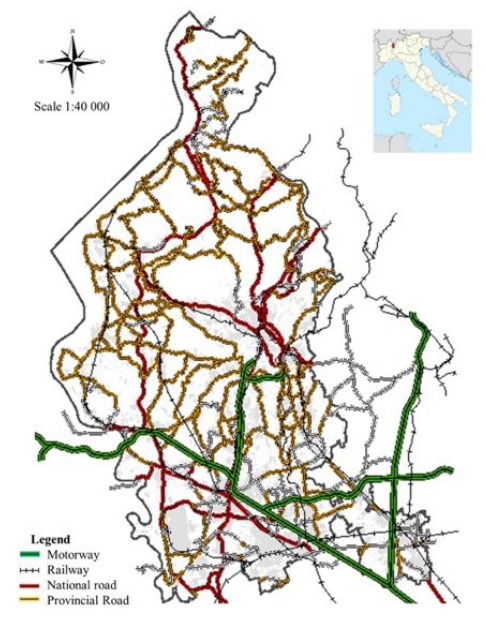

Fig. 1. Study area [24]

The DSS is fed by many types of information [19]:

- description of the transport stream (number of yearly loaded transport units per substance or category);

- description of the transport units;

- description of the transport routes; 
- description of the number of accidents and level of traffic to determine accident frequencies;

- description of ignition sources;

- chemical characteristics and properties of transported substances;

- terrain classification of the surroundings of the transport route (urbanized, agricultural area, etc.);

- meteorological data;

- population living and working in the area surrounding the transport route (density of population);

- location of critical targets with high vulnerability (hospitals, schools, etc.).

All of these types of data feed the algorithms utilized for risk assessment [25].

The model and maps have been integrated into GIS software that can simulate the risk assessment for every road/rail/pipeline tract. When new data are generated, the system can be easily updated. The following are the main characteristics of the software:

- accessible standard language that is compatible with the most common operating systems;

- user interface for selection of roads, rail and pipeline streams;

- results can be geo-referenced into a technical regional map.

Users can select the area of interest and can move with a friendly pan operator. The software automatically shows the data associated with the selected tract, particularly the following:

- $\lambda=$ incident frequency of the selected tract (number of accidents yearly per $\mathrm{km}$ );

- $\mathrm{L}=$ length of the tract $(\mathrm{km})$;

- $\mathrm{NT}=$ hazardous traffic flows;

- $\mathrm{A}=$ impact area $\left(\mathrm{km}^{2}\right)$;

- $\mathrm{DW}=$ population in the environment associated with the selected tract.

Fifty-four substances (6 for each transport class) were considered, including hydrofluoric acid, ammonia, gasoline, benzene, liquefied oxygen, ethylene dioxide, methanol, sulfuric acid, and acetylene, along with their corresponding potential accident scenarios: flash fire, pool fire, UVCE, toxic release, BLEVE, and jet fire.

The first step corresponds to the identification of the transport stream with the characteristics of the hazardous flux. The most important parameters are $\lambda$ (accident frequency), $L$ (length of the tract) and $N T$ (hazardous traffic daily flow). Data are visualized with GIS software. The user can select a road tract, and the software automatically identifies critical parameters. The quantified risk analysis is performed by considering different types of accident scenarios, taking into account that one substance can lead to more than one type of accident (for example, fire and toxic release). The evaluation of physical effects on human health is calculated using off-line software (TNO Effects) that can quantify the distance, in meters, of the threshold limits from the transport road line. The typical scenario (critical events) considered are the following [26, 27]:

- dispersion (release of substances that are toxic, flammable or dangerous to human health without fire);

- pool fire (flammable liquid);

- flash fire (vapor cloud fire without explosive effects);

- UVCE (unconfined vapor cloud explosion);

- BLEVE (boiling liquid expanding vapor explosion);

- jet fire (flammable pressurized gas).

A distinction is made between the following transport classes:

- flammable liquid transported in an atmospheric tank unit;

- flammable or toxic gas compressed or liquefied;

- compressed cryogenic flammable or toxic gas;

- compressed flammable gas. 
The software was applied to all existing road and rail networks in the Varese district (using data on hazardous goods flows, specific incidence rates for every $\mathrm{km}$ of the networks, etc.).

\section{Results and discussions}

The present study facilitated the evaluation of risk and related potential consequences regarding the transportation of hazardous substances and goods in the territory of the Varese district. In particular, the study defined the distribution of individual average risk in the territory (yearly probability/person).

The most dangerous transportation infrastructures are:

- the Motorway A8 (Milan-lakes district), with an individual risk up to $3.713 \mathrm{E}^{-4}$ prob. person/year;

- Como-Chiasso Motorway A9 (in the tract in Varese district) where the peak value of the yearly individual risk (Figure 2) on a $5 \mathrm{~km}$ way is $2.871 \mathrm{E}-4$;

- airport Milan Malpensa highway SS336 (1.268 E-4).

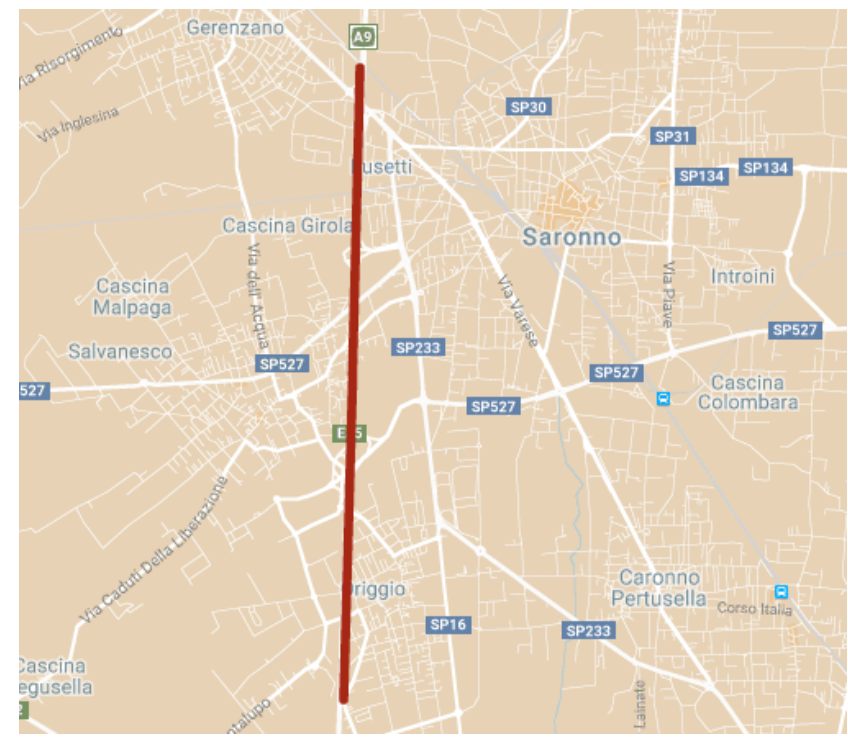

Fig. 2. Evidence of the $5 \mathrm{~km}$ of Motorway tract with the highest value of individual risk in the Como-Chiasso Motorway A9 (2.871 E-4)

The authors fixed the target of $1 \mathrm{E}^{-4}$ as the individual risk maximum level. The mitigation intervention was the detour from road to rail of a part of the total amount of hazardous goods transported. Such adjustment requires considerable expansion of the existing intermodal pole in Busto and the realization of a new one. The combination of transport by road and by rail facilitates the following:

- transportation cost reduction (fewer personnel and lower energy and fuel consumption);

- the reduction of accident risk and environmental effects (in particular, air emissions and noise), increasing safety for people and protection for the environment.

The authors utilized the software in the current scenario, and we compared the results with those corresponding to different scenarios obtained by increasing the percentage of hazardous goods transported by rail (covering the same paths) instead of by roads, since transport risk decrease considerably [28]. In Figure 3 the results regarding the individual risk peak on the ordinate axis and the percentage detour on the abscissa axis, are reported. 
The authors consider the point at which there is a significant change in the slope of the curve. After this point, we have a small reduction of risk level. The optimum value of the percentage of detour from road to rail is $40 \%$. The increased capacity of the intermodal poles corresponds to this percentage.

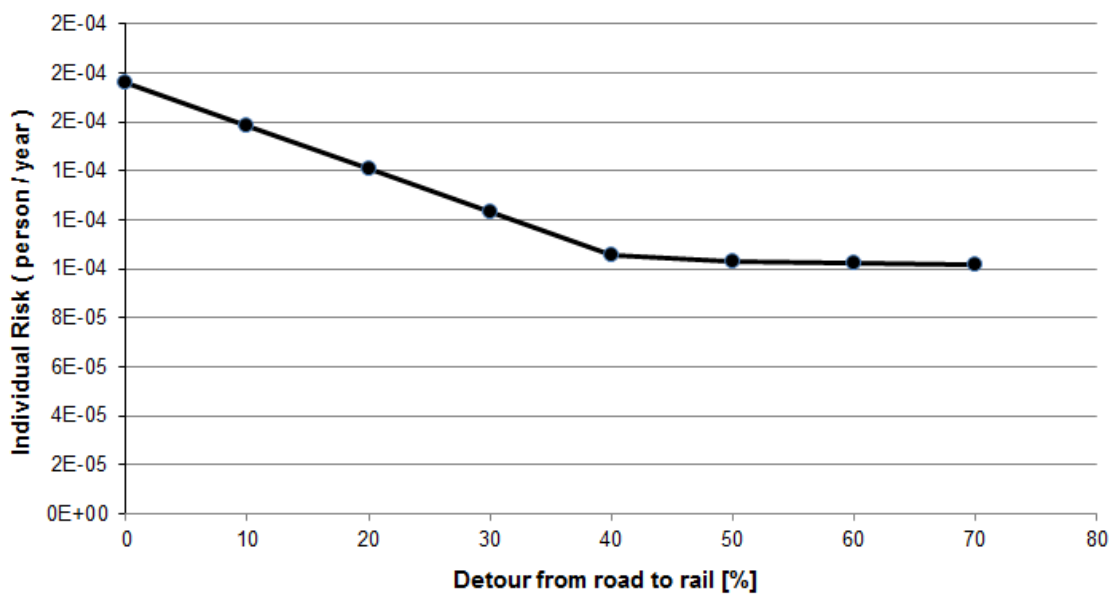

Fig. 3 Example of application of the risk curve to SS 336 (percentage vs. individual risk).

\section{Conclusions}

Decision-support systems have been found to be valuable tools for the management of dangerous goods and for crisis prevention, which increasingly rely on complex information technology architectures and powerful communication technologies. Such technologies are mature, but there are operational constraints related to the cost of the communication. Therefore, the challenge for the coming years is not to improve the available technology but to define a feasible and sustainable business model to reduce the operative costs of public controllers and decision makers and to stimulate competitiveness among private operators. Private sectors have put considerable efforts into improving safety and security of dangerous goods transportation, although improvements are still required. Public authorities need to improve control and monitoring activities, which requires large investments of public economic funds. Despite recent events, such as the Viareggio accident (June 29, 2009), rail transport remains the safest way to transport hazardous goods. Nevertheless, it is necessary to improve the safety level of rail networks and rail tanks. In general, rail transport makes use of proper housing and does not interact with other vectors (as road traffic does). Rail is a means of transport with higher safety levels and lower environmental impact than road transport, and it requires only $50 \%$ of the energy demands of road transport.

This study facilitated the evaluation of a new operative scenario corresponding to a significantly lower level of individual risk distribution in the territory (not higher than E-5). The main conclusions and recommendations of the study are as follows:

a) based on the current data, the optimal percentage of detour from road to rail transportation is $40 \%$;

b) referring to (a), increasing the total intermodal capacity in the district territory from $1,000,000$ to $3,000,000$ tons year ${ }^{-1}$ of hazardous goods;

c) decrease of individual risk (always and everywhere lower than 10-5), with a maximum level of 9.365 E-5 evaluated in a tract of Motorway A8. 
These figures demonstrate that railway can play a strategic role in the optimization of the hazardous goods transportation.

\section{References}

1. P. Cassini, J. Hazard. Mater. 61(1), 133-138 (1998)

2. G.B. Băbuţ, R.I. Moraru, L.I. Cioca, Quality - Access to Success 16(147), 85-91 (2015)

3. Directive 2012/18/EU of the European Parliament and of the Council of 4 July 2012 on the control of major-accident hazards involving dangerous substances, amending and subsequently repealing Council Directive 96/82/EC Text with EEA relevance.

4. C. Di Mauro, J.P. Nordvik, Decision support system for crisis management planning (EC, JRC, Ispra, Italy, 2010)

5. C. Di Mauro, S. Bouchon, V. Torretta, Chem Eng Transact, 26, 297-302 (2012)

6. B. Fabiano, F. Curro, E. Palazzi, R. Pastorino, J. Hazard. Mater., 93(1), 1-15 (2001)

7. R.V. Gagliardi, V. Torretta, F. Conti, S. Stella, G.C. Bello, P. $3^{\text {rd }}$ IASME/WSEAS Int. Conference, Crete, Greece, (2007)

8. V. Torretta, P. CBEE, Singapore (2009)

9. I.L. Balan, L.I. Cioca, V. Torretta, L. Talamona. Procedia Technol. 22, 1028-1034 (2016)

10. M. Verma, V. Verter, Eur. J. Oper. Res. 202(3), 696-706 (2010)

11. S. Contini, P.M. Contini, V. Torretta, C.S. Cattaneo, M. Raboni, S. Copelli, Chem. Eng. Transact. 53, 109-114 (2016)

12. S. Contini, S. Copelli, V. Torretta, M. Raboni, C. Sala Cattaneo, R. Chem. Eng. Transact. 33, 487$492(2013)$

13. D.E. Popescu, C. Bungau, M. Prada, C. Domuta, S. Bungau, D.M. Tit, J. Environ. Prot. Ecol., 17(3), 1011-1020 (2016)

14. V. Torretta, E.C. Rada, M. Ragazzi, E. Trulli, I.A. Istrate, L.I. Cioca, Waste Manag., 45(SI), 152$160(2015)$

15. S. Bungău, R. Suciu, A. Bumbu, G. Cioca, D.M. Tit, J. Environ. Prot. Ecol., 16(3), 980-987 (2015)

16. A.V. Gheorghe, J. Birchmeier, D. Vamanu, I. Papazoglou, W. Kröger. Reliability Eng. Sys. Saf. 88(3), 247-272 (2005)

17. V. Torretta, E.C. Rada, M. Schiavon, P. Viotti, Safe Sci. 92, 1-9 (2017)

18. V. Torretta, M. Raboni, S. Copelli, A.G. Capodaglio, Environ. Eng. Manag. J. 13(10), 2643-2652 (2014)

19. V. Torretta, M. Raboni, S. Copelli, G. Urbini, Environ. Eng. Manag. J. 12(10), 2031-2039 (2013)

20. D. Ryland, J. Transport. Plan. Technol. 9(2), 102-134 (1999)

21. ISTAT - Conto nazionale delle infrastrutture e dei trasporti (Rome, Italy, 2008)

22. European transport policy for 2010: time to decide, White Paper, Bruxelles, Belgium (2007)

23. Y.M. Bontekoning, C. Macharis, J.J. Trip, Transport. Res. Part A: Policy Pr. 38(1), 1-34 (2004)

24. http://cartografia.provincia.va.it/maps/mapindex.html (2017)

25. P. Leonelli, S. Bonvicini. G. Spadoni, J. Hazard. Matater, 71(3), $423-437$ (1998)

26. TNO-Guideline for quantitative risk assessment 'Purple Book', CPR18E, Part 2., (The Hague, The Netherlands, 1997)

27. TNO Safety Software - Effects version 7.5 - Modelling the effects of accidental release of hazardous materials. (The Hague, The Netherlands, 2000)

28. M. Verma, Transport. Res. part C: Emerging Technol. 19(5), 790-802 (2011) 